\title{
Abrasive water jet machining of fly ash and metakaolin based geo-polymers
}

\author{
Marimuthu Uthayakumar ${ }^{1, *}$, Ponnambalam Balamurugan ${ }^{1}$, Kinga Korniejenko ${ }^{2}$, Szymon \\ $\mathrm{Gądek}^{2}$, and Dariusz Mierzwiński ${ }^{2}$ \\ ${ }^{1}$ Faculty of Mechanical Engineering, Kalasalingam Academy of Research and Education, \\ Krishnankoil-626126, India \\ ${ }^{2}$ Institute of Materials Engineering, Faculty of Material Engineering and Physics, Cracow University \\ of Technology, Jana Pawła II 37, 31-864 Cracow, Poland
}

\begin{abstract}
In the present study, the abrasive water jet machining (AWJM) of geopolymers prepared from fly ash, metakaolin and sand is discussed. The samples were prepared from sodium promoter, fly ash / metakaolin and sand. The process of activation was made using a 10M sodium hydroxide solution combined with a sodium silicate solution (the ratio of liquid glass - 1:2.5). To produce geopolymers, flakes of technical sodium hydroxide were used and an aqueous solution of sodium silicate (R-145) with a molar module of 2.5 and a density of around $1.45 \mathrm{~g} / \mathrm{cm}^{3}$ the tap water. The alkaline solution was prepared by means of pouring the aqueous solution of sodium silicate over the solid sodium hydroxide. The solution was mixed and left until its temperature stablised and the concentrations equalised, which took around 2 hours. The fly ash, sand and alkaline solution were mixed for around 10 minutes using a low-speed mixing machine (in order to obtain a homogeneous paste). The paste was allowed to dry in the shade. The paper investigates the AWJM studies on the prepared geopolymer specimens with varyied input parameters such as standoff distance (1.2 and $3 \mathrm{~mm})$, water pressure (120, 140 and $160 \mathrm{MPa})$ and feed rate $(5,10$ and $15 \mathrm{~mm} / \mathrm{min})$. The output parameters such as kerf angle and material removal rate (MRR) were studied with the varying combination of input parameters. From the results, the optimal parameters for machining the geopolymer composites were interpreted.
\end{abstract}

\section{Introduction}

Geopolymers are non-inorganic aluminosilicate polymers composed of silicon and aluminium. The chemical composition is similar to zeolites but the structure is amorphous. Geopolymers can replace traditional concrete or composites. Composites made from a geopolymer matrix have better compressive strength and flexural strength than composites made from Portland cement. Geopolymers are environment-friendly as it produces less emission of carbon dioxide $\left(\mathrm{CO}_{2}\right)$ during manufacturing. It is a heat resistant material; it resists heat of up to $1,000^{\circ} \mathrm{C}$. The application of the geopolymer is used in the field of

\footnotetext{
* Corresponding author: uthaykumar@gmail.com
} 
construction industry (construction of pavements, retaining walls, precast bridge decks and water tanks) the automotive industry and the aviation industry [1]. Most active volcanoes are present in Japan. When they erupt, they emit large amounts of volcanic ash. This ash is very cheap and is used to fabricate geopolymers with high heat-resistant qualities [2]. Tools which are produced with the geopolymer resin have better properties than tools which are produced with castable ceramics, chemically bonded ceramics and monolithic graphite [3]. Due to the inorganic polycondensation of geopolymer, it gains a special three-dimensional oxide network structure. This three-dimensional structure favours special features such as high strength, high temperature resistance, water absorption resistance, corrosion resistance and many more advantages. Its applications are limited due to its particularly brittle nature. However, this drawback can be overcome by adding PVC resin to the geopolymer matrix this has the combined effect of improving the thermal stability of PVC [4].

The dumping of waste has bad effects on the environment as it produces various types of pollution. If waste was utilised in a proper way, this would reduce pollution. Waste was used to manufacture the geopolymer is fly ash from coal combustion, blast furnace slag and red mud. In previous research, fly ash has been used to manufacture the geopolymer [5]. High mechanical performance is shown by the composite material. To overtook the load taken by the reinforcement phase, firstly the crack should be initiated by the matrix phase. Manual maintenance proves to be less efficient. Therefore, it is crucial to find a substitute method for the maintenance of the composite or concrete material by itself in this current busy and fast living society. Self-healing materials are one of the choices.

Self-healing is defining as any process which repair damages to themselves without any external diagnosis/intervention of the problem and improves the performance of the composite material. Self-healing is achieved by the incorporation of nutrients, bacteria and spores into the cement matrix. Spores are produced by bacteria and can grow and stay alive for the hundreds of years without water and nutrients. When water from the surrounding enters into the crack, the bacteria starts to grow and produces calcium carbonates $\left(\mathrm{CACO}_{3}\right)$. This $\mathrm{CACO}_{3}$ in the form of precipitates closes the crack and avoids the further entry of water. However, this method is not always practical [6]. Hollow microsphere filled with fly ash geopolymer is used as a reinforced material in the matrix phase to increase the strength and to maintain the considerable low density [7].

The abrasive water jet machining (AWJM) process uses a high-speed stream of abrasive particles assisted by a high velocity jet of water on to the work surface through a smalldiameter nozzle to cut the material. The AWJM possesses the following advantages: no thermal distortion, small machining force, high flexibility and high machining versatility. Due to the rapid development of human society, the demand for new products in the market is increasing day by day. Thus, manufacturing of the product at a large scale become a measurable issue. The manufacturing industry needs a new and advanced technology to convert the raw material into a useful product without time being wasted by changing tools. Abrasive water jet machining is a new technology that is an advancement of traditional technology for the processing of the raw material into useful products with a good surface finish; it provides no thermal distortion, high machining versatility and requires only a small cutting force [8].

High strength alloy and brittle material is effectively machined by AWJM with a good surface finish and no thermal distortion. The high jet pressure increases the cutting depth and increasing material removal rates affect the quality of surface roughness. The high traverse speed reduces the depth of cut and surface quality [9]. AWJM is widely used as it cuts 10 times faster than conventional machining. It is also a cold cutting process [10]. Electrical discharge machining is used to analyse the material removal rates on unidirectional and multidirectional carbon fibre reinforced plastics (CERPs). The tool life 
was improved but material removal rates and surface roughness were out of control. AWJM is more suitable for the machining of composite materials [11].

The aviation industry needs a higher strength to weight ratio from an economic point of view. Higher weights place a higher load on the engines. Thus, the emission of carbon in the environment is also significantly increased. The material used in the aviation industry need to be free from thermal distortion and corrosion, which also having low residual stress and good fire resistance. All of these machining defects can be eliminated by AWJM. AWJM has some limitations, as the jet pressure reduces, the energy needed for cutting the workpiece in the thickness direction is also reduced, due to this less cutting energy, the jet of water will reverse in opposite direction to the cutting jet flow direction. This leads to distorted kerf geometry and increased surfaces roughness [12]. Hard metal alloys that are difficult to machine can be machined by elevating the temperature of AWJM. The high temperature softens the workpiece. Due to this, the yield strength, hardness and strain hardening of the workpiece reduces and the deformation behaviour of the hard-to-machine material changes to allow plastic deformation. This enables difficult-to-machine material to be machined easily with a low energy requirement, which leads to an increase in the material removal rates and productivity [13].

AWJM is most suitable for materials such as glass, ceramics, stone, composites material, and ferrous and non-ferrous alloys, especially brittle material. Increasing the pressure and standoff distance increases the top and bottom kerf width with a smaller increase in the bottom kerf width. If the traverse speed increases, the kerf taper angle also increases. The high flow rates of abrasives particles improve the surface roughness of the material. The high-pressure jet cuts the material easily and depth of the cut is also increased. The cost of production is reduced because the consumption of abrasive particles is low with regard to high jet pressure [14]. In this experiment, a detailed study conducted on various input parameters, such as jet pressure, traverse speed and standoff distance, and the output parameters, such as kerf width, material removal rates and surfaces roughness, are analysed based on these input parameters.

\section{Experimental Setup}

\subsection{Material}

The fly ash was obtained from the Skawina coal power plant (Skawina, Poland). Bituminous coal is used in the power plant. An electrostatic precipitator was used to collect the fine particles of fly ash from the exhaust gas of the coal-fired furnaces. According to Polish law, the fly ash is classified as a combustion by product with the no. 100102 (fly ash from coal).

\subsection{Geopolymer synthesis}

Technical sodium hydroxide flakes and an aqueous solution of sodium silicate (R-145) were used to produce the geopolymer with a molar module of 2.5 and a density of around $1.45 \mathrm{~g} / \mathrm{cm}^{3}$. Tap water rather than distilled water was used. The aqueous sodium silicate solution was poured over the solid sodium hydroxide to make the alkaline solution. The ratio of water/binder was 0.5 for fly ash. The solution was mixed using a low-speed mixer for 15 minutes until a constant temperature and concentration was attained. The prepared paste was left to solidify in a $0.15 \mathrm{~m} \times 0.15 \mathrm{~m} \times 0.15 \mathrm{~m}$ cubic mould placed on a vibration table. The solidified content in the mould was heated to $75^{\circ} \mathrm{C}$ for 24 hours and left to cool 
to ambient temperature. The demoulded samples were stored under controlled conditions of $20^{\circ} \mathrm{C}$ and $60 \%$ humidity.

\subsection{Experimental procedure}

The experiment was performed using an AWJ nozzle with orifice of $0.7 \mathrm{~mm}$ and $0.35 \mathrm{~mm}$, respectively. Garnet of average particle size $180 \mu \mathrm{m}$ was used as an abrasive. The abrasives were allowed to mix with the high-pressure water in the mixing chamber. The flow rate of the garnet was kept constant between $2-3 \mathrm{~g} / \mathrm{s}$. The three different parameters of jet pressure $(120,140$ and $160 \mathrm{MPa})$, traverse speed $(5,10$ and $15 \mathrm{~mm} / \mathrm{min})$ and standoff distance $(1,2$ and $3 \mathrm{~mm})$ were selected to investigate the kerf angle and material removal rates. The kerf width was calculated by Image $\mathbf{J}$ software and the kerf angle was calculated by the formula:

$$
\text { Kerf Angle, } \theta=\tan ^{-1}\left(\frac{W_{t}-W_{b}}{t}\right)
$$

where,

$\mathrm{W}_{\mathrm{t}}=$ top kerf width $(\mathrm{mm})$

$\mathrm{W}_{\mathrm{b}}=$ bottom kerf width $(\mathrm{mm})$

$\mathrm{t}=$ thickness of the material $(\mathrm{mm})$

The material removal rate (MRR) was calculated by the formula:

$$
\operatorname{MRR}=\mathrm{H}_{\mathrm{t}} \mathrm{D}_{\mathrm{i}} \mathrm{f}
$$

where,

$\mathrm{H}_{\mathrm{t}}=$ depth of penetration $(\mathrm{mm})$

$\mathrm{D}_{\mathrm{i}}=$ average kerf width $\left(\frac{W_{t}-W_{b}}{t}\right)(\mathrm{mm})$

$\mathrm{f}=$ traverse speed $(\mathrm{mm} / \mathrm{min})$

\section{Result and Discussion}

Table 1 shows the output responses (Kerf angle and MRR) under the varying input parameters of standoff distance $(1,2,3 \mathrm{~mm})$, pressure $(120,140$ and $160 \mathrm{MPa})$ and speed (5, 10 and $15 \mathrm{~mm} / \mathrm{min})$. L27 orthogonal array is the most preferred design of experiments by many researchers while designing the experiments with 3 or 4 input parameters $[15,16]$. The series of experiments were conducted by varying the above mentioned 3 input parameters based on a L27 orthogonal array.

Table 1. Kerf angle and MRR under varying input parameters.

\begin{tabular}{|c|c|c|c|c|c|}
\hline Exp. No. & $\begin{array}{c}\text { Standoff } \\
\text { Distance } \\
(\mathbf{m m})\end{array}$ & $\begin{array}{c}\text { Pressure } \\
(\mathbf{M p a})\end{array}$ & $\begin{array}{c}\text { Transverse } \\
\text { speed } \\
(\mathbf{m m} / \mathbf{m i n})\end{array}$ & Kerf Angle & MRR \\
\hline 1 & 1 & 120 & 5 & 0.011 & 3655.6 \\
\hline 2 & 1 & 120 & 10 & 0.034 & 6511.6 \\
\hline 3 & 1 & 120 & 15 & 0.078 & 9166.8 \\
\hline 4 & 1 & 140 & 5 & 0.091 & 3875 \\
\hline
\end{tabular}




\begin{tabular}{|c|c|c|c|c|c|}
\hline 5 & 1 & 140 & 10 & 0.017 & 6466.6 \\
\hline 6 & 1 & 140 & 15 & 0.067 & 9699.9 \\
\hline 7 & 1 & 160 & 5 & 0.173 & 3791.6 \\
\hline 8 & 1 & 160 & 10 & 0.268 & 7383.2 \\
\hline 9 & 1 & 160 & 15 & 0.111 & 9939.9 \\
\hline 10 & 2 & 120 & 5 & 0.302 & 3755.5 \\
\hline 11 & 2 & 120 & 10 & 0.281 & 7600 \\
\hline 12 & 2 & 120 & 15 & 0.077 & 9734.4 \\
\hline 13 & 2 & 140 & 5 & 0.332 & 3744.8 \\
\hline 14 & 2 & 140 & 10 & 0.165 & 20383.35 \\
\hline 15 & 2 & 140 & 15 & 0.229 & 10167 \\
\hline 16 & 2 & 160 & 5 & 0.197 & 3977.9 \\
\hline 17 & 2 & 160 & 10 & 0.176 & 7689.2 \\
\hline 18 & 2 & 160 & 15 & 0.144 & 10566.9 \\
\hline 19 & 3 & 120 & 5 & 0.154 & 4122.3 \\
\hline 20 & 3 & 120 & 10 & 0.067 & 7066.6 \\
\hline 21 & 3 & 120 & 15 & 0.058 & 9825 \\
\hline 22 & 3 & 140 & 5 & 0.122 & 4078 \\
\hline 23 & 3 & 140 & 10 & 0.033 & 7178.2 \\
\hline 24 & 3 & 140 & 15 & 0.1 & 10299.9 \\
\hline 25 & 3 & 160 & 5 & 0.033 & 4211.2 \\
\hline 26 & 3 & 160 & 10 & 0.133 & 7556 \\
\hline 27 & 3 & 160 & 15 & 0.144 & 9700.5 \\
\hline & & & & & \\
\hline
\end{tabular}

\subsection{Effect of pressure and feed rate on the kerf angle}

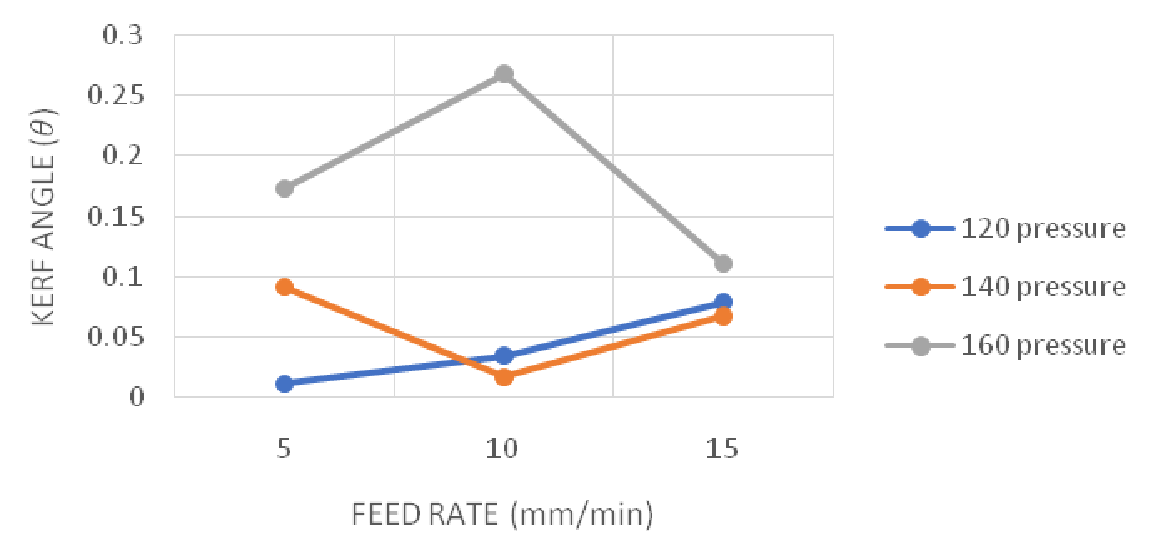

Fig. 1. Kerf angle at $1 \mathrm{~mm}$ standoff distance. 
From Fig. 1, it can be seen that the satisfactory kerf angle was achieved at $120 \mathrm{MPa}$ and at $5 \mathrm{~mm} / \mathrm{min}$ traverse speed as a slow and steady traverse speed provides enough time to cut the specimen and the water jets possess enough kinetic energy. When the traverse speed(feed rate) increases, the jet is not having enough time and energy to cut through the entire thickness of the material due to which the kerf thickness at the top of the surface will be more and the bottom of the specimen will be less, due to which the kerf angle increases, as the feed rate increases, the kerf angle increases.

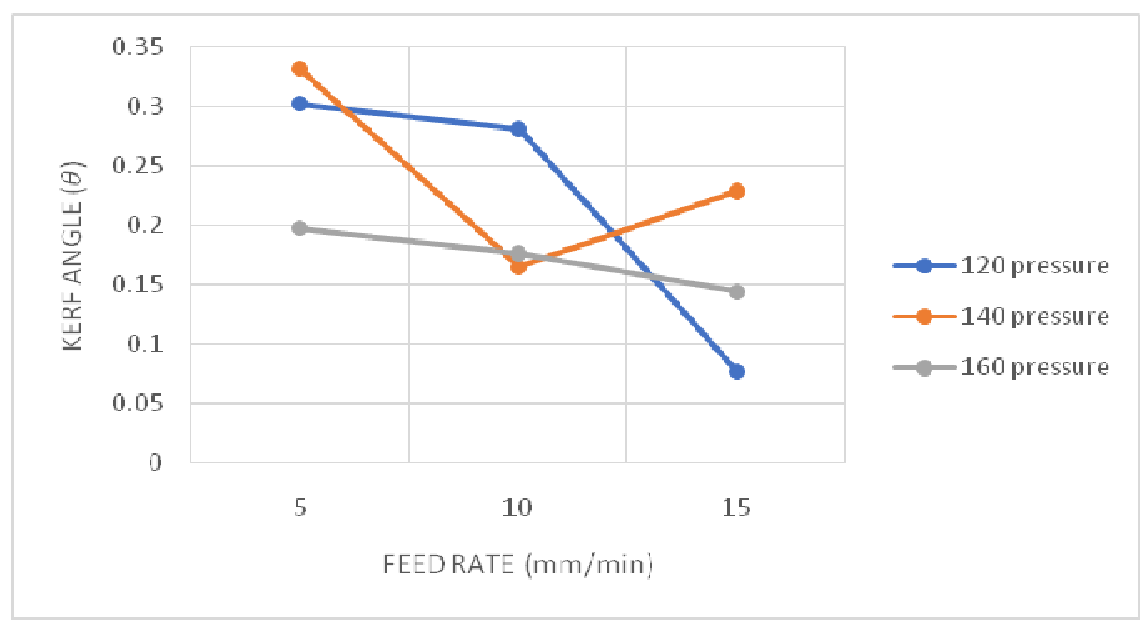

Fig. 2. Kerf angle at $2 \mathrm{~mm}$ standoff distance.

From Fig. 2, the kerf angle achieved at $120 \mathrm{MPa}$ and $15 \mathrm{~mm} / \mathrm{min}$ traverse speed was good. The maximum kerf angle was obtained at $140 \mathrm{MPa}$ pressure and $5 \mathrm{~mm} / \mathrm{min}$ traverse speed.

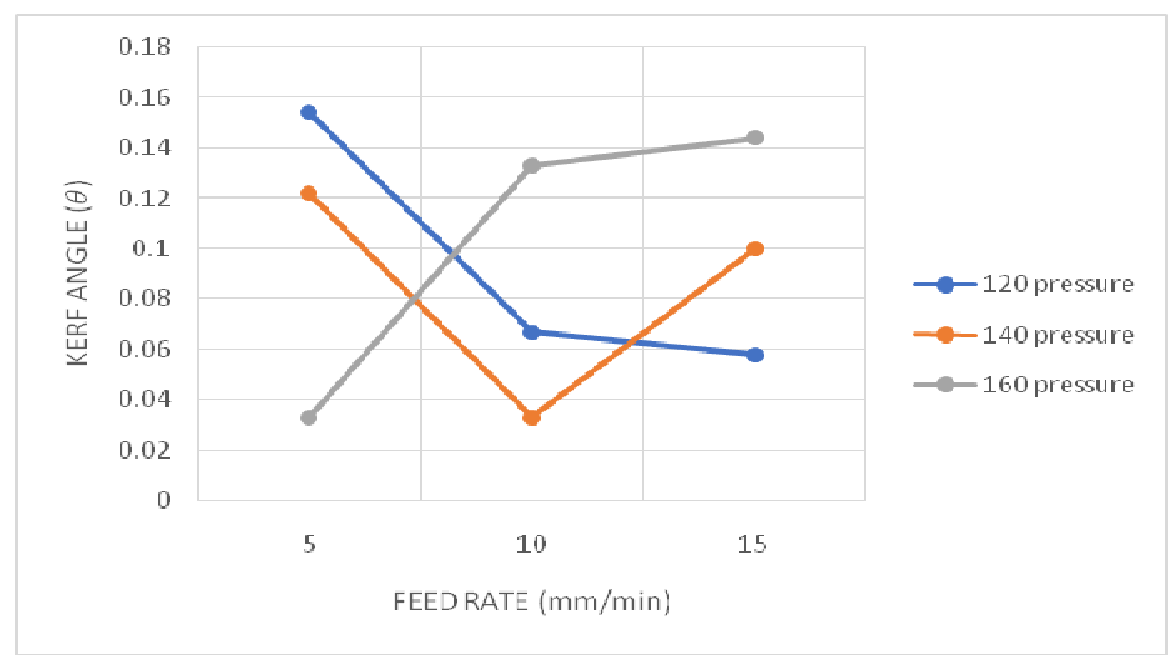

Fig. 3. Kerf angle at $3 \mathrm{~mm}$ standoff distance.

As the standoff distance increases, the uniform behaviour of kerf angle was not achieved as can be inferred from Fig.3. This is because the water jet scattered and the kinetic energy of the jet is continuously reduced. The minimum kerf angle is achieved at $160 \mathrm{MPa}$ and $5 \mathrm{~mm}$ feed rate for the standoff distance $3 \mathrm{~mm}$ which is in contradiction with standoff distance 
$1 \mathrm{~mm}$ in which minimum kerf angle is achieved at $120 \mathrm{MPa}$, the reason is due to, as the standoff distance increases, the scattering of water increases, which will reduce the kinetic energy of water which reaches the specimen which ultimately reduces the cutting power. the rise in standoff distance is compensated by the increase in pressure which results in low kerf angle.

\subsection{Variation of MRR with traverse speed at different pressures}

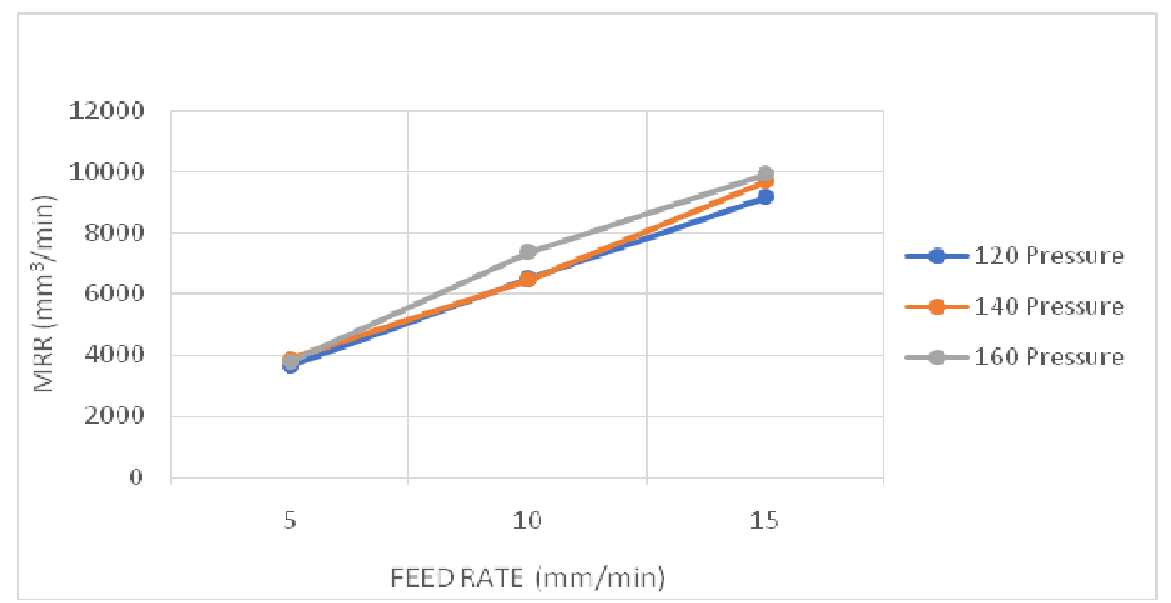

Fig. 4. MRR at $1 \mathrm{~mm}$ standoff distance.

The MRR shows uniform variation of traverse speed along with increasing pressure. The high pressure has high kinetic energy, which increases the material removal rate. The rise in pressure didn't significantly affect the MRR, since the change in jet pressure significantly influence only on the kerf angle, if the change in kerf angle is small it does not have much effect on the MRR. In the experiments conducted the maximum kerf angle is 0.332 which will not have significant effect on the MRR.

\section{SOD 2}

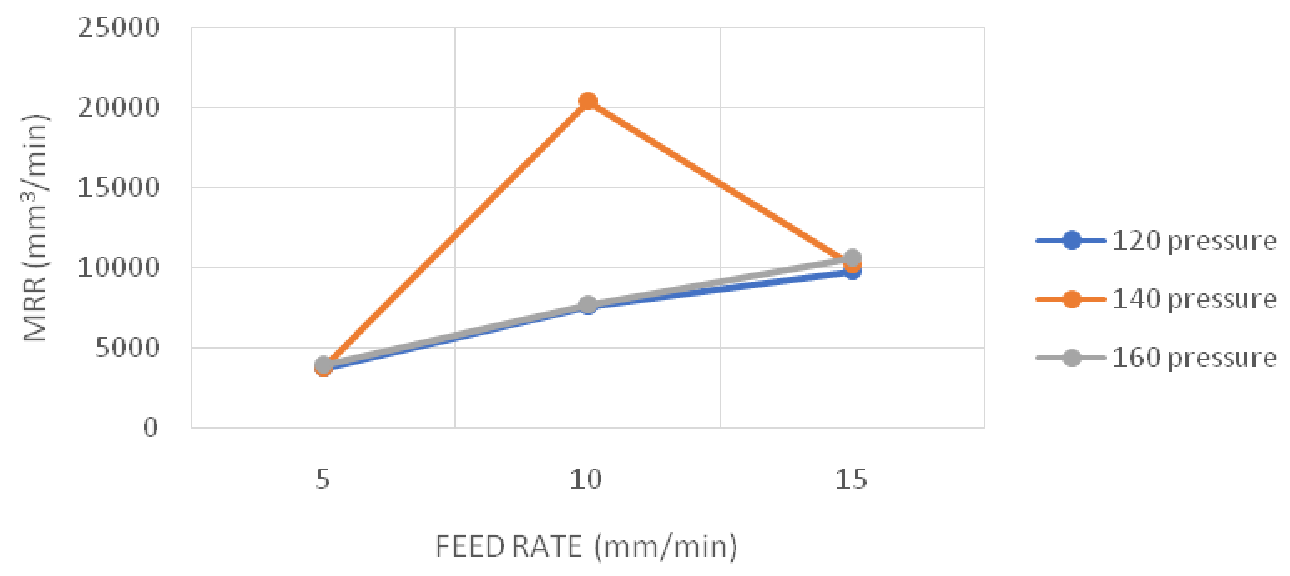

Fig. 5. MRR at $2 \mathrm{~mm}$ standoff distance. 
The maximum MRR was achieved at $140 \mathrm{MPa}$ and at a traverse speed of $10 \mathrm{~mm} / \mathrm{min}$. The $120 \mathrm{MPa}$ and $160 \mathrm{MPa}$ pressures show uniform variation.

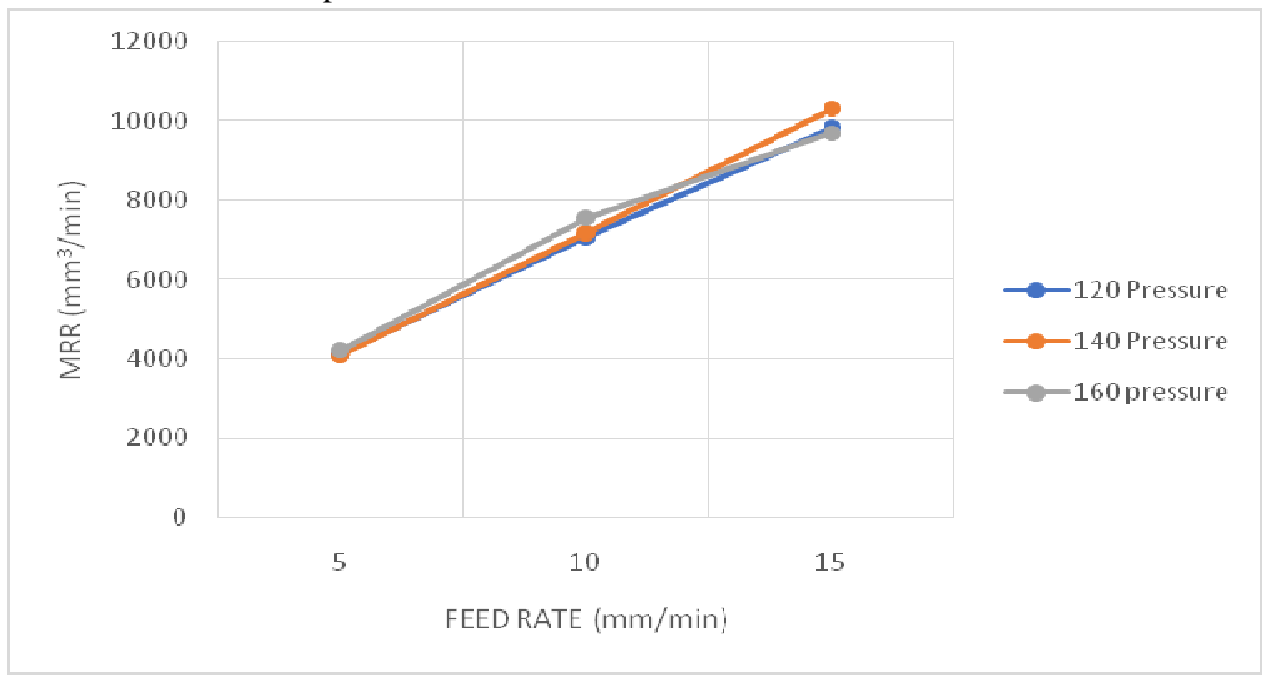

Fig. 6. MRR at $3 \mathrm{~mm}$ standoff distance.

The elevated standoff distance reduces the material removal rates because the kinetic energy of the water jet was reduced.

\section{Conclusion}

Abrasive water jet machining of geopolymer composites was performed and the following conclusions were drawn:

- A precise cut was observed in all experimental condition and it is evident through the kerf taper.

- With the input parameters of low traverse speed, low SOD and high pressure, a low kerf angle is formed.

- Parameters with high pressure and high traverse speed produce a high rate of removal of material.

\section{References}

1. M. Lach, J. Wajs, C. Tempka, K. Korniejenko, J. Mikula, Fibre-reinforced Composites with Geopolymer Matrix: Fiber-Geopolymers (J. Mikula, K. Korniejenko (eds.), Innovative, Cost-Effective and Eco-friendly Fibre-based Materials for the Construction Industry, Wydawnictwo Politechniki Krakowskiej, Cracow, 41-50, 2015)

2. H. Takeda, S. Hashimoto, H. Kanie, S. Honda, and Y. Iwamoto, Ceram. Int., 40, 3 (2014)

3. J. Davidovits, M. Davidovics, Geopolymer. Ultra-high temperature tooling material for the manufacture of advanced composites (International SAMPE Symposium and Exhibition, 36, 2, 1991)

4. K. tuo Wang, Y. He, X. ling Song, X. min Cui, Appl. Clay Sci., 114, 586-592 (2015)

5. S. K. Amin, S. A. El-Sherbiny, A. A. M. A. El-Magd, A. Belal, M. F. Abadir, Constr. Build. Mater., 157, 610-620 (2017) 
6. M. Alshaaer, Constr. Build. Mater. 245 (2020).

7. N. N. Shao, Z. Liu, Y. Y. Xu, F. L. Kong, D. M. Wang, Mater. Lett. 161, 451-454 (2015)

8. S. Saravanan, V. Vijayan, S. T. Jaya Suthahar, A. V. Balan, S. Sankar, M. Ravichandran, Mater. Today Proc. 21, 116-122 (2020)

9. A. Bagchi, M. Srivastava, R. Tripathi, S. Chattopadhyaya, Mater. Today Proc. 27, 2239-2242 (2020)

10. W. N. F. Mohamad, M. S. Kasim, M. Y. Norazlina, M. S. A. Hafiz, R. Izamshah, S. B. Mohamed, Results Eng. 6, 1-3 (2020)

11. S. T. Kumaran, T. J. Ko, M. Uthayakumar, M. M. Islam, J. Alloys Compd. 724, 10371045 (2017)

12. R. Pahuja, M. Ramulu, M. Hashish, Compos. Part B Eng. 175 (2019)

13. D. Patel, P. Tandon, CIRP J. Manuf. Sci. Technol. 10, 92-101 (2015)

14. V. Bhandarkar, V. Singh, and T. V. K. Gupta, Mater. Today Proc. 23, 647-650 (2020)

15. A. K. Rouniyar, P. Shandilya, Mater. Today Proc. 5, 23779-23788 (2018)

16. R. Senthil Kumar, S. Gajendran, R. Kesavan, Mater. Today Proc. 5, 11208-11218 (2018). 